\title{
Not so FAST. Commentary on the article "Appraisal of the faecal haemoglobin, age and sex test (FAST) score in assessment of patients with lower bowel symptoms: an observational study"
}

Joaquín Cubiella®i

\begin{abstract}
A recent study by Digby et al. in BMC Gastroenterology evaluated the faecal haemoglobin, age and sex test (FAST) score in the assessment of patients with lower bowel symptoms attended in primary healthcare. This article is a valuable source of information but the conclusions must be carefully assessed. Authors evaluated the FAST score threshold with a $99 \%$ sensitivity $(\geq 2.12)$ for colorectal cancer (CRC). Although the number of patients meeting this criteria is high, 53.5\% of the patients not referred initially to secondary healthcare, the results on the patients referred to colonoscopy validate the prediction model. The sensitivity and the specificity for CRC detection were 99.0 and $23.2 \%$ with a positive and negative predictive value of 8.0 and $99.7 \%$. Additionally, the sensitivity and the specificity for significant bowel disease were 96.1 and 26.2\% with a positive and negative predictive value of 24.3 and $96.1 \%$, consistent with our initial results. To conclude, although we need the information regarding the risk of CRC in those patients not referred to colonoscopy, a FAST Score $<2.12$ allows to determine a group of patients with a low risk of CRC detection that requires no further evaluation.
\end{abstract}

Keywords: Colorectal cancer, Faecal haemoglobin, Colonoscopy, Prediction models

\section{Main text}

Colorectal cancer (CRC) diagnosis in symptomatic patients attended in primary healthcare is like looking for a needle in a haystack: symptoms are extremely frequent but CRC is rare [1]. The diagnosis of CRC is based on colonoscopy, an invasive technique with limited availability and associated with severe complications in 1/

This comment refers to the article available at https://doi.org/10.1186/ s12876-019-1135-5.

Correspondence: joaquin.cubiella.fernandez@sergas.es

Department of Gastroenterology, Complexo Hospitalario Universitario de

Ourense, Instituto de Investigación Sanitaria Galicia Sur, Centro de

Investigación Biomédica en Red Enfermedades Hepáticas y Digestivas, C/

Rúa Ramón Puga 52-56, 32003 Ourense, Spain
1000 patients [2]. The delay in the diagnosis may worsen prognosis [3] or, at least, produce anxiety. Two practical questions need to be answered: 1.Is the risk of CRC detection so high that patient should be evaluated in a short period of time, i.e. two week time? 2. Is the risk so low that we can assure no additional evaluation is required? With respect to the first question, health systems have proposed several alternatives, mainly based on symptoms, with limitations on its performance. In this sense, the National Institute for Health and Care Excellence (NICE) referral guideline for suspected cancer NG12 proposes to refer to further evaluation those patients with at least a 3\% risk of CRC [4]. In this respect, faecal immunochemical test (FIT) has proven a realistic

(c) The Author(s). 2020 Open Access This article is licensed under a Creative Commons Attribution 4.0 International License, which permits use, sharing, adaptation, distribution and reproduction in any medium or format, as long as you give appropriate credit to the original author(s) and the source, provide a link to the Creative Commons licence, and indicate if changes were made. The images or other third party material in this article are included in the article's Creative Commons licence, unless indicated otherwise in a credit line to the material. If material is not included in the article's Creative Commons licence and your intended use is not permitted by statutory regulation or exceeds the permitted use, you will need to obtain permission directly from the copyright holder. To view a copy of this licence, visit http://creativecommons.org/licenses/by/4.0/ The Creative Commons Public Domain Dedication waiver (http://creativecommons.org/publicdomain/zero/1.0/) applies to the data made available in this article, unless otherwise stated in a credit line to the data. 
and objective option to evaluate symptomatic patients and to determine those patients with higher risk [5]. But, on the other side, no strategy has been proposed to exclude further evaluation mainly due to the limited discriminatory ability of the available strategies, including FIT. In this sense, we proposed that symptomatic patients should not be referred to colonoscopy if the risk of CRC detection is similar to the risk of severe complications associated to colonoscopy [6, 7].

In the last years, we have developed and, afterwards, validated two CRC prediction models in symptomatic patients referred to colonoscopy based on demographics, symptoms, blood determinations and FIT $[6,7]$. COLONPREDICT is a complex prediction model based on eleven variables -age, sex, faecal and blood haemoglobin $(\mathrm{Hb})$, carcinoembryonic antigen, acetylsalicylic acid treatment, previous colonoscopy, rectal mass, benign anorectal lesion, rectal bleeding and change in bowel habit with an area under the curve (AUC) of 0.92 in the derivation and validation cohorts [6]. In contrast, FAST Score, developed in collaboration with the Dundee team, is an easy to calculate prediction model based solely on the faecal $\mathrm{Hb}$ concentration, age and sex. The AUC obtained in the same cohorts where COLONPREDICT was developed and validated was 0.88 [7]. Both prediction models were designed with two thresholds based on 90 and $99 \%$ sensitivity. The first threshold (COLONPREDICT $\geq 5.60$, FAST $\geq 4.50$ ) defines a high risk group in which $90 \%$ of CRCs are detected. On the contrary, the second threshold (COLONPRE$\mathrm{DICT}<3.50$, FAST $<2.12$ ) defines a low risk group in which $1 \%$ of CRC would be detected and, on account of a negative predictive value higher than $99 \%$, no further evaluation should be recommended. The results in the validation cohort were promising and, as an example, $42.4 \%$ of the patients referred to colonoscopy met the low risk criteria according to COLONPREDICT Score, had a negligible risk of CRC and could be evaluated without performing a colonoscopy. In contrast, in the validation cohort of the FAST Score, only $18.8 \%$ were classified as low risk. Although these prediction models provide an opportunity for an objective evaluation of the risk of CRC detection and the allocation in the proper diagnostic strategy, our results must be validated in prospective primary healthcare studies evaluating symptomatic patients.

The study conducted by Jayne Digby and colleagues [8] is aimed at evaluating the diagnostic performance of FIT in symptomatic patients evaluated in primary healthcare. The authors present data from the first year of routine use of $\mathrm{f}-\mathrm{Hb}$ in NHS Tayside, Scotland in the evaluation of patients with new bowel symptoms [9]. Within this study, the authors have performed the validation of the FAST Score in primary healthcare. The authors show the findings related to the number of patients that met a FAST score $>2.12$ and the diagnostic performance in those patients referred to colonoscopy. The good news is that this analysis validates our results. In the 1569 referred to colonoscopy (either immediately or at a later date), $1227(78.2 \%)$ had a FAST $\geq 2.12$. The sensitivity and the specificity were, as expected, $99.0 \%$ (98/99) and $23.2 \%$ (341/1470) with a positive predictive value of $8.0 \%$ and, more importantly, a negative predictive value of $99.7 \%$. So, patients with a FAST score $<2.12$ had a $0.3 \%$ risk of CRC detection, within the expected ranges that allow to exclude referral to colonoscopy. The bad news is that, as authors clearly highlight, $53.5 \%$ of the patients not referred initially to secondary healthcare, had a FAST Score $\geq 2.12$. In this sense, we miss the information regarding the follow-up of the 3803 patients not referred to colonoscopy during a $2-3$ year period in order to identify those undetected CRC. This information would allow to validate, or at least recalibrate, the FAST Score in this population. But we must keep in mind that the threshold evaluated was designed to identify, at least $99 \%$ of CRC and to select a group of patients that do not require further evaluation. In this sense, with the available results, we can confirm that patients with a FAST score $<2.12$ have a CRC risk very similar to the risk of colonoscopy complications and, thus, colonoscopy should not be recommended.

I would like to add several comments to the results of this article. First of all, I miss the information regarding the diagnostic accuracy of the threshold with a $90 \%$ sensitivity (FAST 24.50 ). As previously commented, this threshold was designed to define a high risk group that should be referred immediately for further evaluation. It would be very helpful to know how many patients met this criteria and the sensitivity and positive predictive values in contrast with the $\mathrm{f}-\mathrm{Hb} \geq 10 \mu \mathrm{gr} / \mathrm{gr}$ of faeces recommended in the NICE guideline [10]. It would also be of help to know the positive predictive value for CRC of the patients in the intermediate risk group (FAST Score between 4.50 and 2.12) as long these patients probably benefit from a clinical reevaluation (wait and see strategy) as the authors highlight.

Authors have evaluated the diagnostic accuracy of the FAST Score to detect significant bowel disease (SBD). In the original articles, we validated the first prediction models for the detection of SBD. The results presented by Digby et al. are consistent with our initial findings. In the patients referred to colonoscopy, the sensitivity and the specificity were $96.1 \%(299 / 311)$ and $26.2 \%$ (928/1258) with a positive predictive value of $24.3 \%$ and, a negative predictive value of $96.1 \%$. I would highlight the difficulty of the non-invasive diagnosis of SBD. Besides, the prognosis or the response to therapy in patients with SBD (advanced adenomas, serrated lesions or inflammatory bowel disease) is not clearly affected by the delay in the diagnosis. 
To conclude, the analysis published by Digby and colleagues [8] validates the diagnostic performance of the FAST Score in symptomatic patients referred to colonoscopy for CRC detection. However, its applicability is limited due to the high positivity rate at the 2.12 threshold and the limited sensitivity for SBD detection. Additional information regarding follow-up in those patients without colonoscopy is required in order to confirm the FAST Score $<2.12$ as a criteria to avoid unnecessary colonoscopies.

\section{Abbreviations}

AUC: Area under the curve; CRC: Colorectal cancer; FAST: Faecal haemoglobin, age and sex test; NICE: National Institute for Health and Care Excellence; FIT: Faecal immunochemical test; SBD: Significant bowel disease

\section{Acknowledgments}

Not applicable.

\section{Author's contributions}

Joaquin Cubiella is the sole author of this article. The author wrote, read and approved the final manuscript.

\section{Funding}

Joaquin Cubiella is funded by Instituto de Salud Carlos III through the project PI17/00837 (Co-funded by European Regional Development Fund/ European Social Fund "A way to make Europe"/"Investing in your future").

Availability of data and materials

Not applicable.

\section{Ethics approval and consent to participate}

Not applicable.

\section{Consent for publication}

Not applicable.

\section{Competing interests}

Joaquín Cubiella has financial support from Instituto de Salud Carlos III but has no financial relationships with any organisations that might have an interest in the submitted work in the previous five years, and no other relationships or activities that could appear to have influenced the submitted work.

Received: 15 January 2020 Accepted: 28 May 2020

Published online: 20 July 2020

\section{References}

1. Vega P, Valentín F, Cubiella J. Colorectal cancer diagnosis: pitfalls and opportunities. World J Gastrointest Oncol. 2015;7:422-33.

2. Cubiella J, Marzo-Castillejo M, Mascort-Roca JJ, Amador-Romero FJ, BellasBeceiro B, Clofent-Vilaplana J, et al. Clinical practice guideline. Diagnosis and prevention of colorectal cancer. 2018 update. Gastroenterol Hepatol. 2018; 41:585-96.

3. Alonso-Abreu I, Alarcón-Fernández O, Gimeno-García AZ, Romero-García R, Carrillo-Palau M, Nicolás-Pérez D, et al. Early colonoscopy improves the outcome of patients with symptomatic colorectal cancer. Dis Colon Rectum. 2017:60:837-44.

4. National Institute for Health and Clinical Excellence. Suspected cancer: recognitioin and referral [Internet]. NICE Guidel. 2017 [cited 18 Mar 2018]. Available from: https://www.nice.org.uk/guidance/ng12.

5. Pin Vieito $N$, Zarraquiños $S$, Cubiella J. High-risk symptoms and quantitative faecal immunochemical test accuracy: systematic review and meta-analysis. World J Gastroenterol. 2019;25:2383-401.

6. Cubiella J, Vega P, Salve M, Diaz-Ondina M, Alves MT, Quintero E, et al. Development and external validation of a faecal immunochemical testbased prediction model for colorectal cancer detection in symptomatic patients. BMC Med. 2016;14:128.
7. Cubiella J, Digby J, Rodríguez-Alonso L, Vega P, Salve M, Díaz-Ondina M, et al. The fecal hemoglobin concentration, age and sex test score: development and external validation of a simple prediction tool for colorectal cancer detection in symptomatic patients. Int J Cancer. 2017;140: 2201-11.

8. Digby J, Strachan JA, Mowat C, Steele RJC, Fraser CG. Appraisal of the faecal haemoglobin, age and sex test (FAST) score in assessment of patients with lower bowel symptoms: an observational study. BMC Gastroenterol. 2019;19: $1-7$.

9. Mowat C, Digby J, Strachan JA, McCann R, Hall C, Heather D, et al. Impact of introducing a faecal immunochemical test (FIT) for haemoglobin into primary care on the outcome of patients with new bowel symptoms: a prospective cohort study. BMJ Open Gastroenterol. 2019;6:e000293.

10. Quantitative faecal immunochemical tests to guide referral for colorectal cancer in primary care [Internet]. [cited 2017 Mar 11]. Available from: https://www.nice.org.uk/guidance/dg30.

\section{Publisher's Note}

Springer Nature remains neutral with regard to jurisdictional claims in published maps and institutional affiliations.
Ready to submit your research? Choose BMC and benefit from:

- fast, convenient online submission

- thorough peer review by experienced researchers in your field

- rapid publication on acceptance

- support for research data, including large and complex data types

- gold Open Access which fosters wider collaboration and increased citations

- maximum visibility for your research: over $100 \mathrm{M}$ website views per year

At $\mathrm{BMC}$, research is always in progress.

Learn more biomedcentral.com/submissions 